\title{
Ionic Liquid Crystalline Systems Consisting of Polyammonium and Counter Carboxylate Ions
}

\author{
Shiori Tomitaka, Masanori Nata, Seiji Ujiie* \\ Department of Applied Chemistry, Faculty of Engineering, Oita University, Oita, Japan \\ Email address: \\ tomitaka-shiori@oita-u.ac.jp (S. Tomitaka),manata@oita-u.ac.jp (M. Nata), seujiie@oita-u.ac.jp (S. Ujiie) \\ ${ }^{*}$ Corresponding author
}

To cite this article:

Shiori Tomitaka, Masanori Nata, Seiji Ujiie. Ionic Liquid Crystalline Systems Consisting of Polyammonium and Counter Carboxylate Ions. Advances in Materials. Vol. 5, No. 6, 2016, pp. 73-76. doi: 10.11648/j.am.20160506.13

Received: December 7, 2016; Accepted: December 29, 2016; Published: January 24, 2017

\begin{abstract}
Novel ionic liquid crystals consisting of polyammonium and carboxylate ions were synthesized by ion complexation of polyethyleneimine and carboxylic acids ( $\alpha, \omega$-dicarboxylic acids and hydroxyalkanoic acid). Their thermal properties and orientational behavior were examined by polarizing microscopic observation, differential scanning calorimetry, and variable temperature X-ray diffraction measurements. The ionic liquid crystals exhibited thermotropic liquid crystalline phases. The ionic liquid crystals $(\mathrm{BP} / n \mathrm{dA})$ bearing counter dicarboxylate ions formed a cubic phase upon heating and cooling. On the other hand, the ionic liquid crystal bearing the counter hydroxyalkanoate ion exhibited enantiotropic smectic A and smectic B phases with focal conic fan textures. These ionic liquid crystalline phases were formed by ionic and hydrophobic interactions because they did not have an aromatic mesogenic group.
\end{abstract}

Keywords: Ionic Liquid Crystal, Ionic Interaction, Polyammonium, Thermal Property, Orientational Behavior, Cubic, Smectic A, Smectic B

\section{Introduction}

In liquid crystalline systems, the noncovalent bond interaction, such as hydrogen bonding, donor-acceptor interaction, and ion interaction, plays an important role in the liquid crystal formation, thermal property, and orientation behavior. Introduction of ionic groups into liquid crystal molecules leads to the formation of thermotropic smectic phases with enhanced thermal stability [1-10]. Liquid crystal formation in ionic liquid crystalline systems strongly depends on ionic interactions. Furthermore, the ionic liquid crystalline system consists of both ionic and nonionic groups. The ionic groups aggregate and segregate from the nonionic groups. In such a case, a microphase separation occurs and induces liquid crystal formation. In ionic liquid crystalline systems, aromatic mesogenic groups are not necessarily required for liquid crystal formation [11-13]. A balance between ionic and hydrophobic interactions is important to form a liquid crystalline phase with enhanced thermal stability. For example, $\mathrm{N}$-dodecylpyridinium chloride forms smectic A, columnar, and cubic phases. However, $N$-stearylpyridinium chloride exhibits only a smectic A phase [14].

In ionic liquid crystalline systems, ionic groups such as ammonium, carboxylate, and sulfonate salts effectively form liquid crystals and enhance the thermal stability of the liquid crystalline alignment. Previously, ionic liquid crystalline systems without aromatic mesogenic groups were synthesized by ion complexation (a proton-transfer reaction) of polyethyleneimine and alkanoic acids $[15,16]$. These ionic liquid crystalline systems exhibited a smectic A phase with an oily-streak texture and a homeotropic alignment upon heating and cooling. In the smectic A phase, which occurs due to a microphase separation through ionic interactions, a higher fluidity was observed. This result showed that the proton-transfer reaction was a useful method to obtain these liquid crystalline systems. The high fluidity of the smectic A phase is attributed to the fact that the ionic interaction becomes weaker with increasing temperature.

In this work, we synthesized novel ionic liquid crystalline systems through ion complexation of polyethyleneimine and carboxylic acids. Liquid crystal formation of these ionic liquid crystalline systems, their thermal properties, and orientational behavior are described herein. 


\section{Experimental}

\subsection{Materials}

Liquid crystalline ion complexes (ionic liquid crystalline systems) were prepared by mixing a carboxylic acid (CA) (16-hydroxyhexadecanoic acid (16hA), dicarboxylic acid $(n \mathrm{dA})$; where " $n$ " refers to the number of carbon atoms: $n=11$, $13,15)$ and branched polyethyleneimine $(\mathrm{BP} ; \mathrm{MW}=1,800)$ (Figure 1). The synthesis was carried out according to the literatures $[15,16]$. Solutions of CAs and $\mathrm{BP}$ (the rate of " $\mathrm{CA}$ : amine unit of BP" was weighed 1:4 molecular ratio) were prepared in tetrahydrofuran (THF) and methanol, respectively. The $n \mathrm{dA}-\mathrm{THF}$ solution was added dropwise to the BP-methanol solution under ultrasonic vibration at room temperature. The resulting mixture became cloudy. After the reaction, the solvent was allowed to evaporate at room temperature. The crude ion complex product was washed with THF, which was allowed to evaporate at room temperature. The ion complex $(\mathrm{BP} / n \mathrm{dA})$ was then dried under reduced pressure. In IR measurements, $\mathrm{BP} / n \mathrm{dA}$ exhibited a stretching vibration of the carboxylate ion $\left(\mathrm{COO}^{-}\right)$. For example, the stretching vibration of carboxylate ion in $\mathrm{BP} / 15 \mathrm{dA}$ was observed at $1639 \mathrm{~cm}^{-1}$. However, the $\mathrm{C}=\mathrm{O}$ stretching vibration of $15 \mathrm{dA}$ (dicarboxylic acid) appeared at $1699 \mathrm{~cm}^{-1}$, which was not measured in $\mathrm{BP} / 15 \mathrm{dA}$. This result indicates that the carboxyl groups of $15 \mathrm{dA}$ completely changed to carboxylate ions through the proton-transfer reaction. $\mathrm{BP} / 16 \mathrm{hA}$ was also obtained through the same method (the rate of "16hA: amine unit of BP" was weighed 1:2 molecular ratio).

\subsection{Measurements}

Thermal properties were examined by polarizing microscopic observation (Mettler-Toledo FP900-HP82 system) and differential scanning calorimetry (DSC; Shimadzu DSC60i). Variable temperature X-ray diffraction measurements were performed with a Shimadzu XRD6100/TTK-450 to examine the orientational structure of the liquid crystalline phases.<smiles>CCCNCC(C)(C)CCN(C)C</smiles>

$M W=1800$<smiles>O=C(O)CCCCCCCCCCC(=O)O</smiles>
THF, MeOH

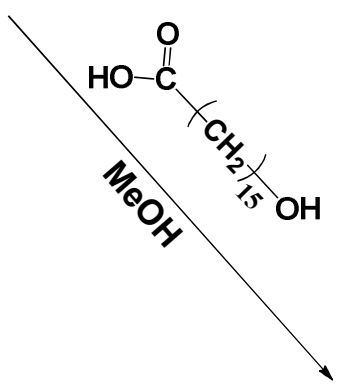

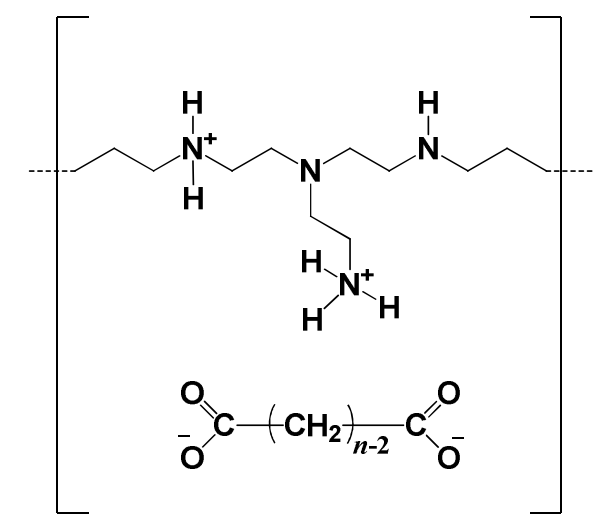

(A)

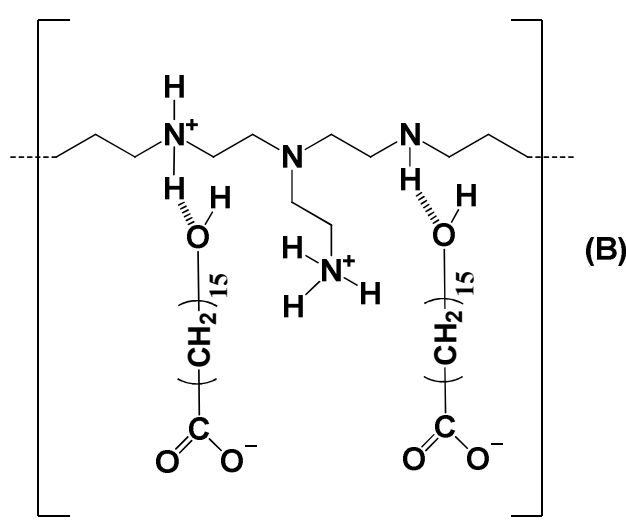

Figure 1. Synthetic scheme of ion-complexes through the proton-transfer reaction of branched polyethyleneimine and carboxylic acids. (A): 50\% of the amine residues remain, (B): 50\% of amine residues remain. 16-Hydroxyhexadecanoate ions form hydrogen bond exhibiting a broken line as well as ionic interaction.

\section{Results and Discussion}

\subsection{Thermal and Optical Properties}

The DSC curves for $\mathrm{BP} / n \mathrm{dA}(n=11,13)$ indicated a secondary transition from a glass state to a liquid crystalline phase. However, a liquid crystalline-isotropic phase transition was not clearly found. The liquid crystalline-isotropic phase transitions of $\mathrm{BP} / n \mathrm{dA}(n=11,13)$ cannot be determined by polarizing microscopy, due to the optically isotropic liquid-crystalline phases. A dark field was observed under a crossed Nicol. An optical interference figure (isogyre) was not obtained for the dark field through conoscopic observation. This indicates that the dark field was not perpendicularly aligned [4].

The liquid crystalline behavior of $\mathrm{BP} / 15 \mathrm{dA}$ resembled that of $\mathrm{BP} / n \mathrm{dA}(n=11,13) . \mathrm{BP} / 15 \mathrm{dA}$ revealed the same optical isotropy as $\mathrm{BP} / n \mathrm{dA}(n=11,13)$. On the other hand, the liquid 
crystal (BP/16hA) with 16-hydroxyhexadecanoate ions exhibited smectic A and smectic B phases. In the smectic A and smectic B phases, focal conic fan textures were clearly observed.

Table 1. Phase transitions and X-ray data of ionic liquid crystalline systems.

\begin{tabular}{lll}
\hline Sample & ${\text { Phase Transitions } /{ }^{\circ} \mathbf{C}^{\mathbf{l}}}$ & X-ray data (spacing/nm) \\
\hline $\mathrm{BP} / 11 \mathrm{dA}$ & $\mathrm{g}-8.0 \mathrm{Cub}^{2)}$ & 1.43 \\
$\mathrm{BP} / 13 \mathrm{dA}$ & $\mathrm{g} 4.1 \mathrm{Cub}^{2)}$ & 1.67 \\
$\mathrm{BP} / 15 \mathrm{dA}$ & $\mathrm{g} 4.5 \mathrm{Cub}^{2)}$ & $1.87,1.12,0.95$ \\
$\mathrm{BP} / 16 \mathrm{hA}$ & $\mathrm{g} 64.3 \mathrm{SmB} 83.1 \mathrm{SmA} 110.8 \mathrm{I}$ & $\mathrm{SmB}: 2.37,0.43 . \mathrm{SmA}: 2.25$ \\
\hline
\end{tabular}

1) g: glass, Cub: cubic, SmB: smectic B, SmA: smectic A, I: isotropic.

2) We consider the formation of a cubic phase from three conditions of optical isotropy, lack of perpendicular alignment, and an ordered structure (the X-ray inner reflection).

$\mathrm{BP} / n \mathrm{dA}(n=11,13)$ have a network structure in a solid phase. In the liquid crystalline phases, however, the ionic interaction decreased with increasing temperature, and the reorientation of the alkyl chain of the counter dicarboxylate ions occurs. In that case, $\mathrm{BP} / n \mathrm{dA}(n=11,13,15)$ form the fluid ordered structure such as the cubic or sponge mesophases with a microphase separation.

In the case of $\mathrm{BP} / 16 \mathrm{hA}$, the terminal hydroxyl groups of $16 \mathrm{hA}$ form hydrogen bonding with the amino groups of the polyethyleneimine chain. It is easy for the hydrophobic alkyl chains to form fluid liquid crystalline orientations because the hydrogen bonding is a weaker interaction when compared to the ionic interaction. Furthermore, the hydrogen bonding of the terminal groups leads to the formation of the smectic B phase with enhanced orientational order as well as the smectic A phase.

\subsection{Structural Analysis}

The X-ray diffraction patterns were measured for the $\mathrm{BP} / n \mathrm{dA}$ series. In $\mathrm{BP} / n \mathrm{dA}$ with $n=11,13$, the X-ray inner reflections were obtained in fluid phases. The layer distances obtained from the X-ray inner reflections corresponded to an extended molecular length $(L)$ of $n \mathrm{dA} . \mathrm{BP} / n \mathrm{dA}$ with $n=11,13$ exhibited optical isotropy.

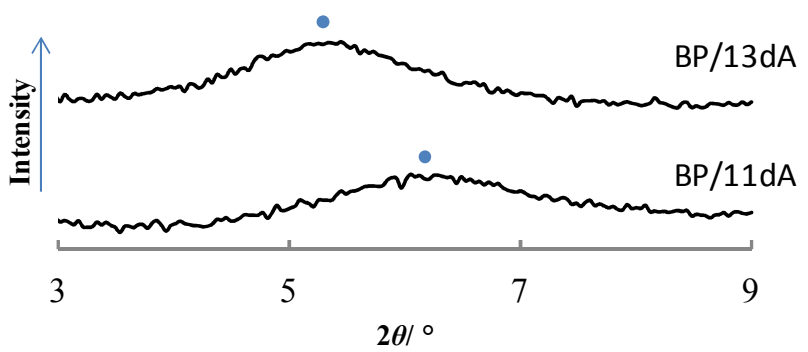

Figure 2. X-ray diffraction patterns of $B P / 11 d A$ and $B P / 13 d A$ at $70^{\circ} \mathrm{C}$. The scan rate is $0.1^{\circ} \mathrm{min}$.

However, the existence of the X-ray inner reflections indicates that some ordered structure was formed in the fluid state. Three conditions, namely: optical isotropy, lack of perpendicular alignment, and an ordered structure (the X-ray inner reflection) indicated the formation of a liquid crystalline phase such as a cubic phase exhibiting optical isotropy. The X-ray inner reflections of $\mathrm{BP} / n \mathrm{dA}$ with $n=11,13$ were not found above $150^{\circ} \mathrm{C}$. This suggests that the liquid crystalline-isotropic phase transition temperatures were about $150^{\circ} \mathrm{C}$.

$\mathrm{BP} / 15 \mathrm{dA}$ revealed the $\mathrm{X}$-ray reflections. We considered that the X-ray reflections corresponded to (220), (222) and (400) (Figure 3). In this case, it is expected that the fluid ordered phase of BP/15dA is a cubic phase such as Pn3m [14].

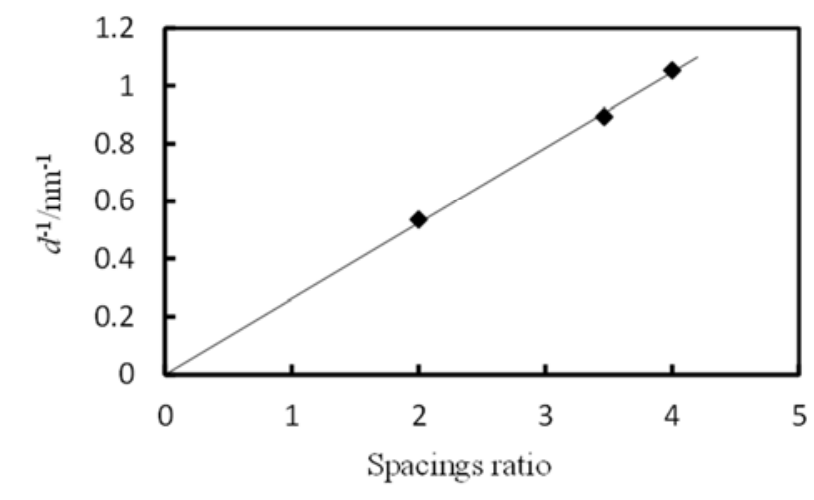

\begin{tabular}{ccc}
\hline hkl & Spacings ratio & $d / \mathrm{nm}$ \\
\hline 200 & 2 & 1.87 \\
222 & $\sqrt{ } 12$ & 1.12 \\
400 & 4 & 0.95 \\
\hline
\end{tabular}

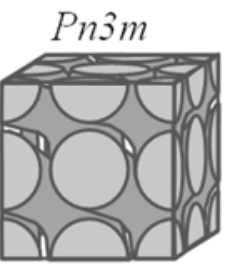

Figure 3. Relationship between spacings ratio and $1 / d$ in $B P / 15 d A\left(70.0^{\circ} \mathrm{C}\right)$. It is expected that BP/15dA forms the cubic phase (Pn3m).
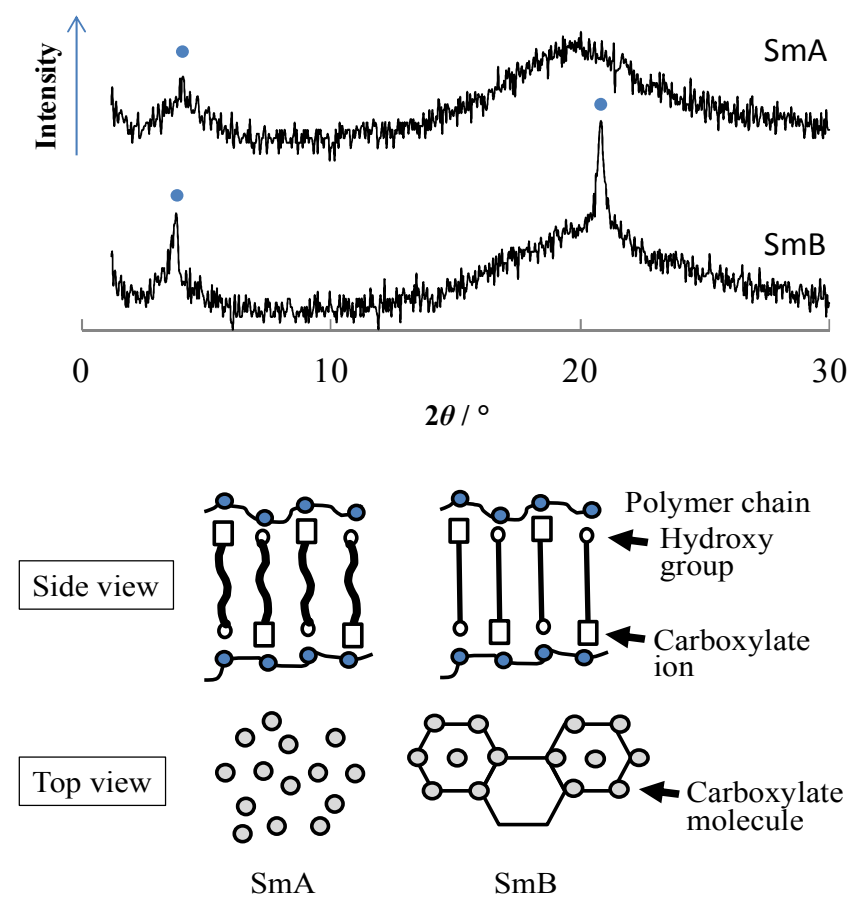

Figure 4. $X$-ray diffraction patterns and possible packing models of smectic $A$ $\left(100^{\circ} \mathrm{C}\right)$ and smectic $B\left(80^{\circ} \mathrm{C}\right)$ phases of $\mathrm{BP} / 16 \mathrm{hA}$.

The X-ray diffraction patterns of $\mathrm{BP} / 16 \mathrm{hA}$ consist of the 
sharp inner reflections and the broad outer reflection in the smectic A phase $\left(100^{\circ} \mathrm{C}\right)$ (Figure 4). In the smectic B phase $\left(80^{\circ} \mathrm{C}\right)$, however, $\mathrm{BP} / 16 \mathrm{hA}$ revealed the X-ray sharp inner and outer reflections (Figure 4). The X-ray sharp inner reflection exhibits the formation of layer structure. The X-ray sharp outer reflection indicates the existence of the ordered smectic phase such as the smectic B phase with a hexatic order within the layer. Possible packing models of the smectic A and smectic B phases are proposed as shown in Figure 4. The layer spacings (SmB: $2.37 \mathrm{~nm}, \mathrm{SmA}: 2.25 \mathrm{~nm}$ ) corresponded to the extended length $(2.02 \mathrm{~nm})$ of $16 \mathrm{hA}$. This indicates the formation of a monolayer structure in the smectic B phase. The smectic A phase also has the monolayer structure. Furthermore, the alkyl chains of 16hA formed a hexatic structure within the smectic B layer. In the smectic A phase, however, the orientation with a short range order (without a positional order) is formed within the layer. In the smectic A and B phases, the layer structures consist of the hydrophilic and hydrophobic sublayers. The orientational structure of the smectic phases is stabilized by the hydrophilic sublayers consisting of polyammonium and counter dicarboxylate ions.

\section{Conclusions}

The novel ionic liquid crystalline systems were synthesized through the proton-transfer reaction of polyethyleneimine and carboxylic acids $(\alpha, \omega$-dicarboxylic acids and hydroxyalkanoic acid). The ionic interaction acted effectively to the formation of the fluid liquid crystalline phases. $\mathrm{BP} / n \mathrm{dA}$ bearing the counter dicarboxylate ions formed the cubic phase. On the other hand, $\mathrm{BP} / 16 \mathrm{hA}$ bearing the counter monocarboxylate ion exhibited the smectic A and smectic B phases. We consider that the balance between ionic and hydrophobic interactions is very important for liquid crystal formation. Since the ionic interaction is strong in the case of $\mathrm{BP} / n \mathrm{dA}$, the reorientation of the hydrophobic alkyl chains is inhibited. In $\mathrm{BP} / 16 \mathrm{hA}$, however, the hydrophobic alkyl chains possess the flexibility to allow a variety of orientations. The liquid crystalline behavior of $\mathrm{BP} / n \mathrm{dA}$ and $\mathrm{BP} / 16 \mathrm{hA}$ will be investigated still more. Thus, we can further clarify the influence of noncovalent interactions such as ionic interaction and hydrogen bonding on the liquid crystal formation.

\section{References}

[1] Handbook of Liquid Crystal Research, edited by P. J. Collings and J. S. Patel, Chapter 8, 329-330, NY (1997).

[2] S. Ujiie and T. Kato, Handbook of Liquid Crystals $2^{\text {nd }}$ edition (Wiley-VCH), edited by J. W. Goodby, P. J. Collings, T. Kato, C. Tschierske, H. F. Gleeson, and P. Raynes, 7, 381-412 (2014).

[3] C. M. Paleos, G. Margomenou-Leonidopoulou, and C. Christias, Mol. Cryst. Liq. Cryst., 137, 391 (1986).

[4] S. Ujiie and K. Iimura, Macromolecules, 25, 3174 (1992).

[5] S. Ujiie and K. Iimura, Chem. Lett., 19, 995 (1990).

[6] S. Ujiie, Y. Tanaka, and K. Iimura, Poly. Adv. Tech., 11, 450 (2000).

[7] S. Ujiie, H. Furukawa, Y. Yano, and A. Mori, Thin Solid Films, 509, 185 (2006).

[8] T. Yoshimi, M. Moriyama, and S. Ujiie, Mol. Cryst. Liq. Cryst., 511, 319 (2009).

[9] J. Wu and S. Ujiie, Mol. Cryst. Liq. Cryst., 563, 67 (2012).

[10] A. A. Fernandez and P. H. J. Kouwer, Int. J. Mol. Sci., 17, 731 (2016).

[11] D. Demus, H. Demus, and H. Zaschke, Flüssige Kristalle in Tabellen, VEB Deutscher Verlag für Grundstoffindustrie, Leipzip (1974).

[12] A. Skoulios and V. Luzzati, Nature, 183, 1310 (1959).

[13] C. Paleos, M. Arkas, R. Seghrouchni, and A. Skoulios, Mol. Cryst. Liq. Cryst., 268, 179 (1995).

[14] S. Ujiie and A. Mori, Mol. Cryst. Liq. Cryst., 437, 1269 (2005).

[15] S. Ujiie, S. Takagi, and M. Sato., High Perform. Polym. 10, 139 (1998).

[16] S. Ujiie, Y. Yano, and A. Mori, Mol. Cryst. Liq. Cryst., 411, 483 (2004). 